\title{
Shaking table testing of an existing masonry building: assessment and improvement of the seismic performance
}

\author{
Nuno Mendes ${ }^{1, *}{ }^{\dagger}$, Paulo B. Lourenço ${ }^{1}$ and Alfredo Campos-Costa ${ }^{2}$ \\ ${ }^{1}$ ISISE, Department of Civil Engineering, University of Minho, Guimarães, Portugal \\ ${ }^{2}$ NESDE, National Laboratory for Civil Engineering, Lisbon, Portugal
}

\begin{abstract}
SUMMARY
This paper aims to assess and improve the seismic performance of an existing masonry building with flexible floors, representative of a Portuguese building typology - 'gaioleiro' buildings. The study involved seismic tests and dynamic identification tests of two models (nonstrengthened and strengthened) in the shaking table. Each model was subjected to several seismic tests with increasing amplitude. Before the first test and after each seismic test, the dynamic identification of the model was carried out, aiming at obtaining their seismic vulnerability curves based on a damage indicator obtained from the decrease of the frequencies of the modes. In the strengthened model, steel elements were used to improve the connection between walls and floors, together with ties in the upper stories. The results show that adopted strengthening technique is effective for reducing the seismic vulnerability of 'gaioleiro' buildings, namely for improving the out-of-plane behavior of the facades. Copyright (c) 2013 John Wiley \& Sons, Ltd.
\end{abstract}

Received 23 December 2012; Revised 12 May 2013; Accepted 10 June 2013

KEY WORDS: earthquake; masonry; seismic performance; strengthening; shaking table

\section{INTRODUCTION}

Natural disasters are an effect of natural hazards such as tornados, volcanic eruptions, landslides, tsunamis, or earthquakes, which caused millions of deaths and severe socio-economic impacts, affecting the development of many countries. From this perspective, earthquakes are one of the most devastating natural hazards on Earth. According to Hough and Bilham [1], earthquakes caused $6 \mathrm{~m}$ fatalities in 500 years (1500-2000). In the last decade, among others, earthquakes in Haiti Region (2010) and Indonesia (2004) alone caused more than half a million deaths [2]. In Portugal, it is estimated that the 1755 earthquake and the subsequent tsunami that occurred in Lisbon destroyed about $85 \%$ of the buildings and about $25 \%$ of the population of Lisbon at that time, totaling about 70,000 deaths [2]. However, earthquakes hardly kill people, being the collapse of the buildings the main reason of the deaths. This means that efforts should be conducted to reduce the seismic vulnerability of buildings.

Existing masonry buildings were built for many centuries taking into account mostly vertical static loads according to the experience of the builder and without reference to any particular seismic code [3]. But also in seismic areas, existing masonry structures represent an important part of the building stock. Thus, the study of the vulnerability of existing buildings is receiving much attention in the recent decades due to the increasing interest in the conservation of the built heritage and the awareness that life and property must be preserved. The different types of masonry present common

*Correspondence to: Nuno Mendes, ISISE, Department of Civil Engineering University of Minho, Guimarães, Portugal.
${ }^{\dagger}$ E-mail: nunomendes @ civil.uminho.pt 
features that provide high seismic vulnerability to these buildings, such as the high specific mass, the low tensile strength, the low to moderate shear strength, and the low ductility (brittle behavior). In addition to the influence of the material properties, the seismic behavior of existing masonry buildings depends on factors such as the geometry of the structure, connections between orthogonal walls, connections between structural walls and floors, connections between walls and roof, the foundation behavior, the stiffness of the floors, and the behavior of the nonstructural elements.

This paper aims at evaluating and improving the seismic performance of an existing masonry building typology through shaking table tests. The adopted masonry building corresponds to a Portuguese building typology ('gaioleiro') has common features with most existing traditional masonry buildings. The buildings of this typology were built between the 19th century and the beginning of the 20th century and are believed to present very high seismic vulnerability. The 'gaioleiro' buildings are, generally, four to six stories high, with stone masonry walls and timber floors and roof, and still remain in use nowadays [4, 5].

Two models were built at reduced scale (nonstrengthened and strengthened) and tested in the 3D shaking table of the National Laboratory for Civil Engineering (LNEC) in Lisbon. The shaking table experimental program included seismic and dynamic identification tests. The seismic load used in the tests is composed of two orthogonal and uncorrelated accelerograms that induce, simultaneously, in-plane and out-of-plane behavior of the models. Furthermore, the seismic action was applied with increasing amplitude at the base of the models i.e. several tests were carried out on the same model. The dynamic identification tests were carried out before the first and after each seismic input, aiming at evaluating the variation of the dynamic properties of the models as a function of the increasing seismic amplitude.

\section{OUTLINE OF THE RESEARCH}

In order to assess the seismic performance of "gaioleiro" buildings, two models (nonstrengthened and strengthened) were tested in the 3D shaking table of the National Laboratory for Civil Engineering (LNEC) in Lisbon. First, the non-strengthened model was built at reduced scale and tested, aiming at obtaining moderate damage and not full collapse. Finally, the non-strengthened model was repaired, strengthened and tested again (strengthened model).

The shaking table experimental program included seismic and dynamic identification tests. The seismic load used in the tests is composed by two orthogonal and uncorrelated accelerograms which induce, simultaneously, in-plane and out-of-plane behavior of the models. The seismic action was applied with increasing amplitude at the base of each model, i.e. several seismic tests were sequentially carried out on the same model. Furthermore, dynamic identification tests were also carried out before the first and after each seismic test, aiming at evaluating the variation of the dynamic properties of the models as a function of the increasing seismic amplitude applied in the models.

\section{PREPARATION OF THE SHAKING TABLE TESTS}

Shaking table tests are able to simulate most accurately the excitation of structures under seismic loading. Basically, the shaking table is a rigid platform, where models are fixed, moved by hydraulic actuators. The most complex shaking tables have six degree of freedom (three translational and three rotational), which require a complex control system. The costs to build this type of facility and the cost of making the models are themselves high. Even if the shaking tables can be rather large, usually the models are prepared at reduced scale given the size of full civil engineering structures. The preparation of models at reduced scale, using laws of similitude, is difficult, but examples of shaking table tests on large structures are given in $[6,7]$.

In this section, a detailed description of the works involved in the shaking table tests of the current testing program are presented, namely the objectives and methodology, definition of the prototype and models, the construction of the models at reduced scale, the characterization of the materials, the test setup and instrumentation, and the generation of the input signals. 


\subsection{Objectives and methodology}

The main objectives of the shaking table tests were to assess the seismic performance of an existing masonry building and to validate the efficiency of a strengthening technique. These objectives were carried out through two experimental procedures: (i) the evaluation of the response of the models based on the results obtained in the seismic tests (namely crack patterns and displacements at floor levels) with increasing seismic amplitude applied at base and (b) the definition of seismic vulnerability curves based on the decrease of natural frequencies of the models with the application of seismic tests with increasing amplitude.

The seismic tests were performed imposing accelerograms compatible with the design response spectrum defined by the Eurocode 8 [8], characterized by a peak ground acceleration (PGA) of increasing amplitude. Thus, several seismic tests were carried out on the same model measuring its response by accelerometers, placed on floor levels, and recording the damage that occurred. It is noted that the model was not repaired before applying the subsequent seismic actions. This means that the model accumulated damage with the shaking table tests and, consequently, the initial conditions are not the same for all tests. The models only present ideal initial condition (absence of damage) in the first seismic test.

The methodology for defining the seismic vulnerability curves through experimental tests is, usually, based on the identification of the dynamic properties of the models (natural frequencies, mode shapes, and damping ratios) along a series of seismic tests with increasing input excitations $[9,10]$. The dynamic properties give inherent information of the model, and its evolution is related to the stiffness and, consequently, to the damage caused by a given seismic input. Thus, dynamic identification tests at the shaking table were carried out, aiming at characterizing the dynamic properties initially and after each seismic input. The tests for the characterization of the dynamic properties were done applying series of white noise accelerations at the base of the models, simultaneously in two orthogonal directions, being the response measured by accelerometers placed at floor levels.

The shaking table tests of the NSM involved four seismic tests with amplitudes equal to $25 \%, 50 \%$, $75 \%$, and $100 \%$ of the code amplitude and five dynamic identification tests. In the SM, two extra seismic tests were performed, with amplitudes of the seismic action equal to $125 \%$ and $150 \%$ of the code amplitude. Because of serious damage of the SM in the last stage, it was not possible to carry out the dynamic identification after the final seismic test.

\subsection{Prototypes and models definition}

The prototype was defined according to the main characteristics of 'gaioleiro' buildings. Candeias [11] carried out a study on the seismic performance of these buildings and defined prototypes representative of the typology, based on the survey of Appleton [5] on 20 'gaioleiro' buildings in Lisbon. Three types of prototypes were defined: (i) an isolated building with rectangular plan; (ii) a semi-detached building with rectangular plan; and (iii) a corner building with irregular plan. Given the fact that the costs and the time requirements in the shaking table tests are very high, only the model of the prototype of the isolated building was considered in this work. The isolated building has two facades with about $30 \%$ of area of openings, two gable walls without openings, timber floors, and a two-slope roof. The prototype has four floors with $3.60 \mathrm{~m}$ of interstory height, thickness of the walls (limestone) constant and equal to $0.51 \mathrm{~m}$, and dimensions in plan equal to $9.45 \times 12.45 \mathrm{~m}^{2}$.

Models are prepared to reproduce the geometrical, physical, and dynamical characteristics of the prototypes. However, models are usually simplified because of difficulties related to its execution in laboratory. Given the size of the prototype and the size and load capacity of the facilities, reduced scale models are usually considered. It is difficult to fulfill the similitude laws using very small scales, for example, with respect to the preparation of masonry units and strengthening elements. Here, because of the size and payload capacity of the LNEC [11] shaking table, the model had to be geometrical reduced to a scale of 1:3. Physically, the similitude corresponds to the equivalence between objects or phenomena that actually are different [12]. For a reduced scale model to be able to reproduce the dynamic behavior of its prototype, it must satisfy the similitude of the following 
[13]: (i) geometry; (ii) relationship between stresses and strains of the constituting materials; (iii) mass and gravity forces; and (iv) initial conditions and boundary conditions.

Geometry similitude is usually obtained from the direct application of the scale factors. This can be difficult to achieve accurately for all the details of the prototype for large scale factors. Stress-strain relationships are much more difficult to reproduce in the models even when the same material is used in the prototype and model. Very reduced scales require the use of specific materials (different from the original ones), and phenomena such as the bond between a reinforcement bar and concrete can be complex to scale. The similitude of mass and gravity forces is obtained using the Cauchy and Froude similitude laws [13]. The Cauchy number, see Equation (1), corresponds to the ratio between inertial forces and restoring forces:

$$
\text { Cauchynumber }=\frac{\rho L^{3} v^{2}}{E L^{2}}=\frac{\rho v^{2}}{E}
$$

and the Froude number, see Equation (2), relates the inertial forces and gravity forces:

$$
\text { Froudenumber }=\frac{\rho L^{3} v^{2}}{\rho L^{3} g}=\frac{v^{2}}{L g}
$$

in which $\rho$ is the specific mass, $L$ is the length, $v$ is the velocity, $E$ is the Young's modulus, and $g$ is the gravity acceleration.

Table I presents the scale factors of several parameters for both similitude laws, assuming that the material of the prototype and the model are the same $\left(E_{p} / E_{m}=1\right)$. Taking into account only the Cauchy similitude law, the accelerations in the model $\left(a_{m}\right)$ are equal to $\lambda$ times (scale factor) the accelerations in the prototype $\left(a_{p}\right)$. However, in the experimental test, it is not possible to scale the acceleration of gravity. This means that the relationship between inertial forces and gravity forces is not respected (Froude number).

Taking into account the size and payload capacity of the shaking table, the Cauchy law of similitude with a scale factor equal to 1:3 was adopted. The same material (limestone and lime mortar) was used in the prototype and the model. The model has four floors, two facades with openings, two gable walls without openings, timber floors, and the top ceiling, which represents the roof in an approximate way.

The models did not include the mass of the partition walls or any live load, as they are almost negligible. The inertial forces of existing masonry buildings are mostly related with the mass of the

Table I. Scale factors of the Cauchy and Froude similitude laws [13].

\begin{tabular}{lccc}
\hline Parameter & Symbol & Cauchy & Cauchy and Froude \\
\hline Length & $L$ & $L_{p} / L_{m}=\lambda=3$ & $L_{p} / L_{m}=\lambda=3$ \\
Young's Modulus & $E$ & $E_{p} / E_{m}=1$ & $E_{p} / E_{m}=\lambda=1$ \\
Specific mass & $\rho$ & $\rho_{p} / \rho_{m}=\lambda=1$ & $\rho_{p} / \rho_{m}=\lambda^{-1}=1 / 3$ \\
Area & $A$ & $A_{p} / A_{m}=\lambda^{2}=9$ & $A_{p} / A_{m}=\lambda^{2}=9$ \\
Volume & $V$ & $V_{p} / V_{m}=\lambda^{3}=27$ & $V_{p} / V_{m}=\lambda^{3}=27$ \\
Mass & $m$ & $m_{p} / m_{m}=\lambda^{3}=27$ & $m_{p} / m_{m}=\lambda^{2}=9$ \\
Displacement & $d$ & $d_{p} / d_{m}=\lambda=3$ & $d_{p} / d_{m}=\lambda=3$ \\
Velocity & $v$ & $v_{p} / v_{m}=1$ & $v_{p} / v_{m}=\lambda^{1 / 2}=3^{1 / 2}$ \\
Acceleration & $a$ & $a_{p} / a_{m}=\lambda^{-1}=1 / 3$ & $a_{p} / a_{m}=1$ \\
Weight & $W$ & $W_{p} / W_{m}=\lambda^{3}=27$ & $W_{p} / W_{m}=\lambda^{2}=9$ \\
Force & $F$ & $F_{p} / F_{m}=\lambda^{2}=9$ & $F_{p} / F_{m}=\lambda^{2}=9$ \\
Moment & $M$ & $M_{p} / M_{m}=\lambda^{3}=27$ & $M_{p} / M_{m}=\lambda^{3}=27$ \\
Stress & $\sigma$ & $\sigma_{p} / \sigma_{m}=1$ & $\sigma_{p} / \sigma_{m}=1$ \\
Strain & $\varepsilon_{p} / \varepsilon_{m}=1$ & $\varepsilon_{p} / \varepsilon_{m}=1$ \\
Time & $\varepsilon$ & $t_{p} / t_{m}=\lambda=3$ & $t_{p} / t_{m}=\lambda^{1 / 2}=3^{1 / 2}$ \\
Frequency & $t$ & $f_{p} / f_{m}=\lambda^{-1}=1 / 3$ & $f_{p} / f_{m}=\lambda^{-1 / 2}=3^{-1 / 2}$ \\
\hline
\end{tabular}

Example with scale factor $\lambda$ equal to 3 .

$p$ and $m$ designate prototype and model respectively. 
thick masonry walls. The self-weight of the models is about $220 \mathrm{kN}$ and the self-weight of the foundation slab is equal to $108 \mathrm{kN}$. Thus, the total mass (model + slab) on the shaking table is about $328 \mathrm{kN}$ and its maximum load capacity is equal to $392 \mathrm{kN}$. The weight of the model was the main reason for selecting only the Cauchy similitude law for construction on a 1:3 reduced scale. If Cauchy and Froude similitude laws had been respected, additional masses had to be added to the models and the total selfweight would be about $768 \mathrm{kN}$, exceeding the load capacity of the shaking table.

\subsection{Models construction}

The geometry of the nonstrengthened model (NSM) (Figure 1) results directly from the application of the scale factor to the prototype, providing an experimental model $3.15 \mathrm{~m}$ wide and $4.15 \mathrm{~m}$ deep, with $0.17 \mathrm{~m}$ of wall thickness. The interstory height is equal to $1.20 \mathrm{~m}$. In the construction of the timber floors, medium-density fiberboard (MDF) panels, with thickness equal to $0.012 \mathrm{~m}$, connected to a set of timber joists oriented in the direction of the shortest span, were used (Figure 1(b)). The panels

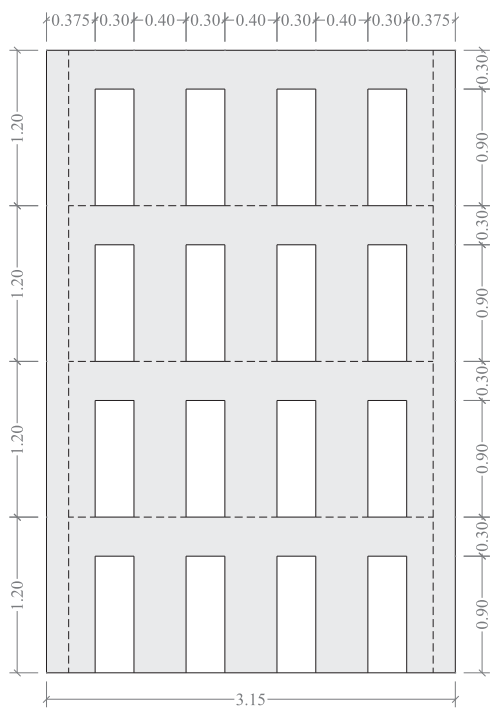

(a)

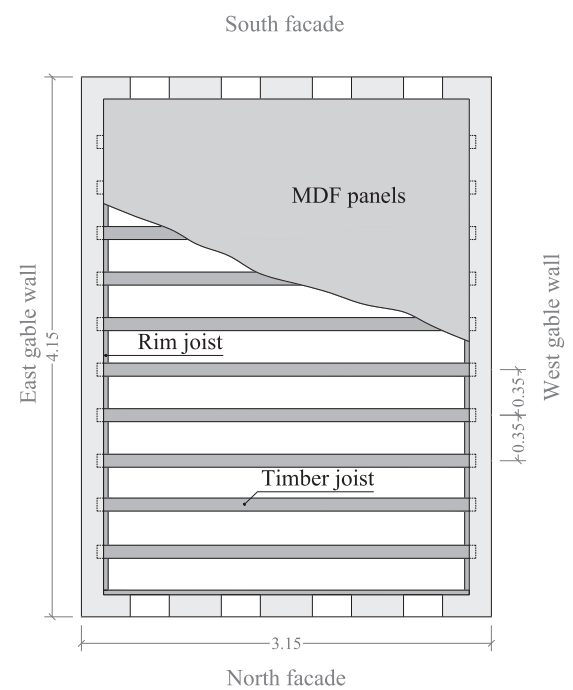

(c)

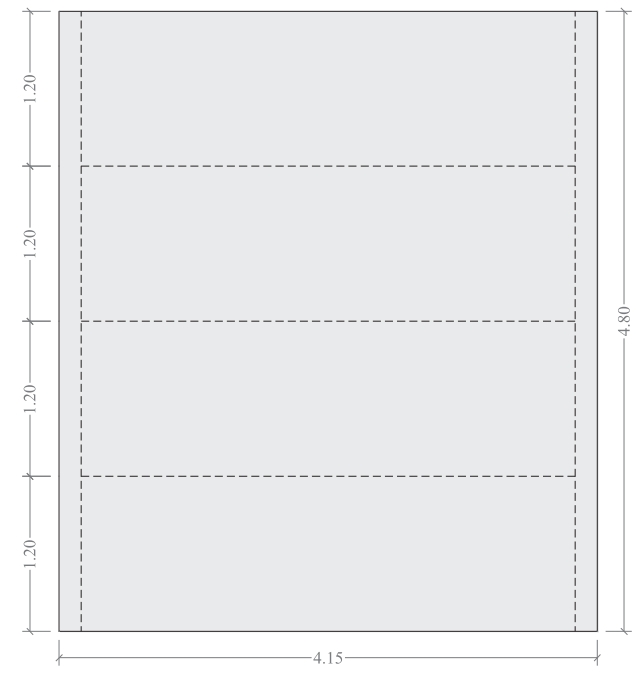

(b)

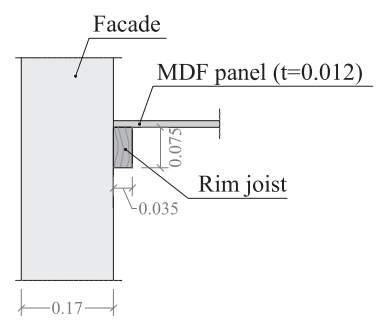

(d)

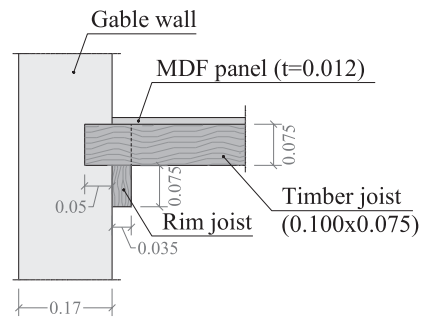

(e)

Figure 1. Geometry of the nonstrengthened model: (a) facades, (b) gable walls, (c) plan, (d) connection floor-gable wall, and (e) connection floor-facade. (Dimensions in meters). 
were cut in rectangles $\left(0.57 \times 1.05 \mathrm{~m}^{2}\right)$ and nailed to the joists, keeping a joint of about $1 \mathrm{~mm}$ for separating the panels. The purpose was to simulate flexible floors with weak diaphragmatic action. In order to avoid elements with small cross section, as a result of application of the scale factor, each timber joist corresponds to a set of three real joists, resulting in a cross section with $0.100 \times 0.075 \mathrm{~m}^{2}$ (width and height) spaced each $0.35 \mathrm{~m}$. The floor has rim joists, connected using bent nails to the gable walls $\left(0.035 \times 0.150 \mathrm{~m}^{2}\right)$, as well as in the facades $\left(0.035 \times 0.075 \mathrm{~m}^{2}\right)$. The timber joists were inserted $0.05 \mathrm{~m}$ into the gable walls (Figure 1(d)). The connection between floors and facades is weaker as the MDF panels are connected to the rim joists, which are only connected to the masonry wall by bent nails (Figure 1(e)).

The strengthened model (SM) (Figure 2) presents the same geometry of the nonstrengthened one. The main goals of the strengthening techniques were to improve the connection between the floors and the masonry walls and to prevent the out-of-plane collapse of the facades. Total or partial collapse of the facades is observed in similar buildings struck by earthquakes. The improvement of the connections between floors and masonry walls was performed using steel angles (S235) at all floor levels placed internally in the model (Figure 2(b)). In the gable walls, the steel angles are connected to the masonry by chemical anchors (M8) spaced each $0.25 \mathrm{~m}$, through the rim joists (Figure 2(c)). The steel angles are also connected to the timber joists and MDF panels by bolts (Figure 2(d)). Additionally, timber elements to constrain the rotation of the timber joists were used (Figure 2(b)). In the facades, the connection between floors and masonry walls was improved using steel angles inside and steel plates outside of the model. These steel elements were interconnected by bolts spaced each $0.25 \mathrm{~m}$ (Figure 2(e)). Furthermore, the connection between MDF panels and rim joists was also improved by additional nails (Figure 2(e)). It is expected that some beam effect prevents the out-of-plane displacements of the facades and improves the in-plane behavior because the spandrels are now connected by steel elements. It is noted that no steel plates were added at the external surface of the gable walls for obvious execution difficulties in practical applications. Although the model is representative of an isolated 'gaioleiro' building, the adopted strengthening techniques aim to be general and should be applicable to the semi-detached buildings.

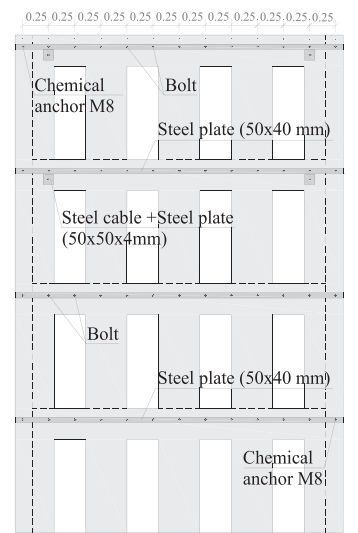

(a)

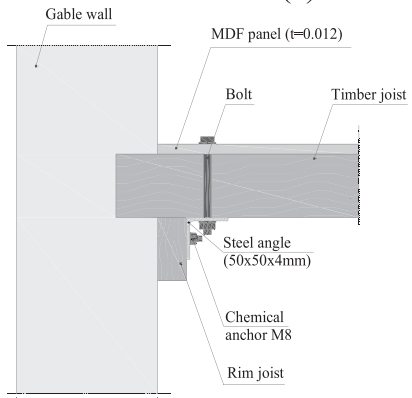

(c)

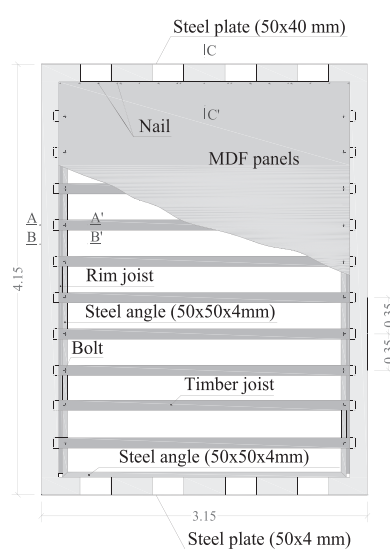

(b)

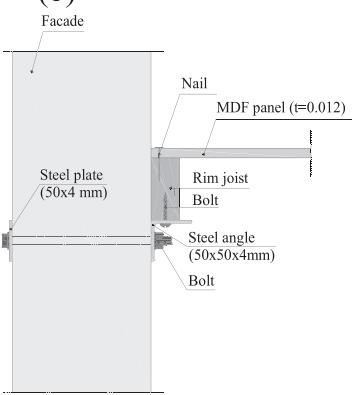

(e)

Figure 2. Strengthened model (a) facades, (b) plan, (c) section AA', (d) section BB', and (e) section CC'. (Dimensions in meters, unless indicated otherwise). 
In the two top floors, steel cables were also installed (Figure 3(a)). Each floor has two pairs of stainless steel cables (AISI 316), with diameter equal to $3 \mathrm{~mm}$, connecting the middle of the facades to the corners of the opposite facades, transferring the inertial forces in the out-of-plane direction of the facades to the plane of the gable walls. The cables are connected to the masonry walls with an external steel plate (Figure 3(b)), preventing punching shear of the masonry, and to the steel angles in the corners and in the middle of facades, respectively. Each steel cable is made by two parts joined by turnbuckles, aiming at providing a slight prestress ( $2 \%$ of the ultimate load).

The construction of the models was made outside of the shaking table on a reinforced concrete slab specifically designed for this purpose. The slab has plan dimensions of $4.40 \times 4.90 \mathrm{~m}^{2}$, elements to lift the model during transportation and holes conveniently drilled to fix the model to the shaking table. The self-weight of the slab is about $108 \mathrm{kN}$ and has to be added to the mass of the models to define the total mass on the shaking table. The NSM was built floor by floor, in a way that the loadbearing walls of a given floor were initially built, followed by the construction of the respective timber floor. The timber floors were built 1 week after the construction of the load-bearing walls to allow partial hardening of the lime mortar. The load-bearing stone walls were built with specialized workmanship.

The seismic test on the NSM aims at obtaining moderate damage and not full collapse. After the seismic tests, the NSM was initially repaired, aiming at re-establishing the initial conditions. Afterwards, the model was strengthened and only then was tested again. First, the strengthening of the connection between floors and masonry walls was carried out, with the installation of the steel angles and their welding in the corners. Then, the steel cables were installed in the two top floors. Figure 4 shows the final aspect of the NSMs and SMs.

\subsection{Material characterization}

During the construction of the NSM, 66 specimens of lime mortar $\left(0.040 \times 0.040 \times 0.160 \mathrm{~m}^{3}\right)$ and 31 specimens of limestone units $\left(0.050 \times 0.050 \times 0.125 \mathrm{~m}^{3}\right)$ were prepared, aiming at characterizing the mechanical properties. The lime mortar is composed of lime, cement, and sand in the proportions of 2:1:6 by volume.

Tests of flexural and compressive strength of the lime mortar, according to the European standards 196-1 [14] and tests of compressive strength of the limestone, according to the standard American Society for Testing and Materials D2938-95 [15], were carried out at LNEC. The age of the mortar specimens is over 28 days. The flexural and compressive strength of the lime mortar is on average equal to 0.65 and $2.47 \mathrm{MPa}$, respectively. The compressive strength of the limestone is on average

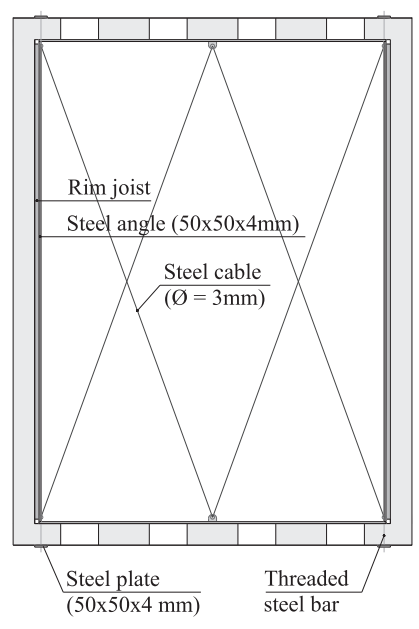

(a)

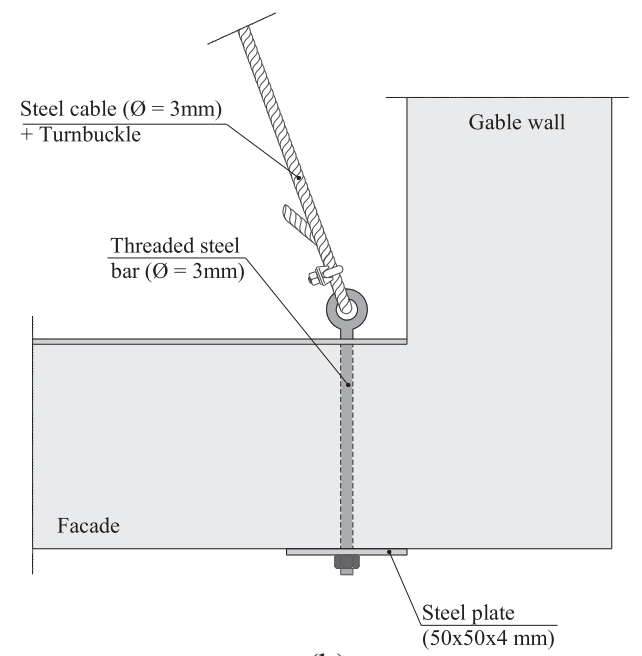

(b)

Figure 3. Steel cables of the strengthened model: (a) plan of the two top floors (floors not represented) and (b) connection of the cables to the corners. 


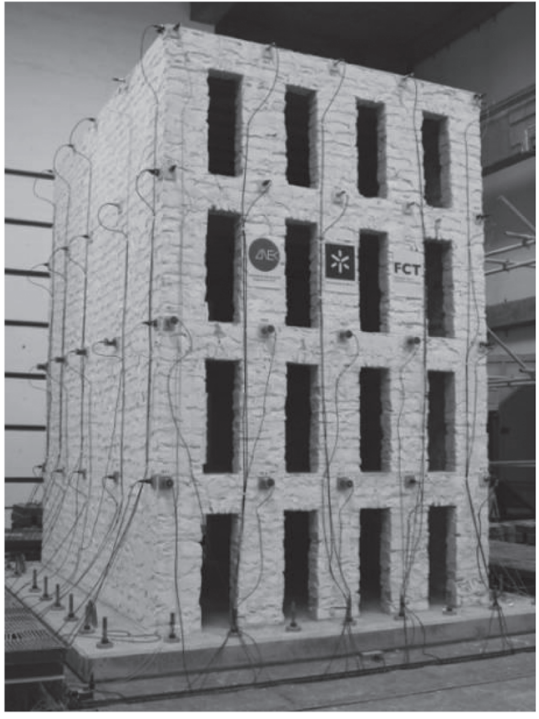

(a)

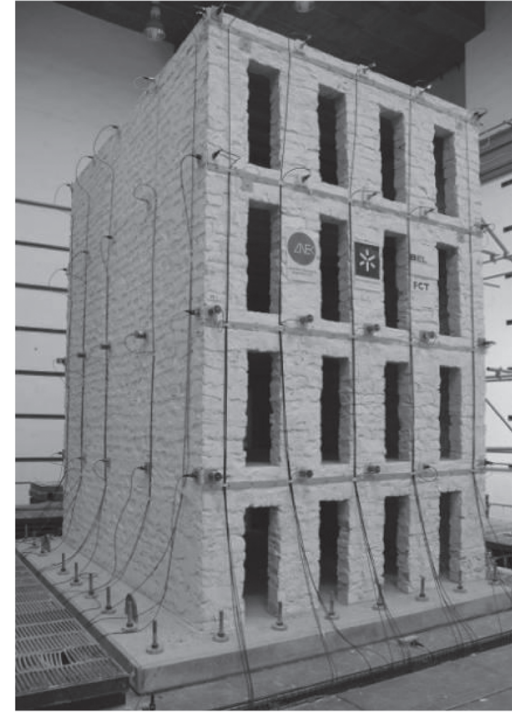

(b)

Figure 4. General views, showing the instrumentation of the model: (a) nonstrengthened model; (b) strengthened model.

equal to $131 \mathrm{MPa}$. As a reference, Toumbakari [16] carried out tests on lime mortar specimens, with proportions 2:1:11 (lime, cement, and sand) by volume, and limestone obtained from demolished buildings in Belgium. The mortar was prepared to reproduce a relatively 'weak' historic mortar. The flexural and compressive strength obtained in the mortar tests were 1.20 and $3.40 \mathrm{MPa}$, respectively. In the limestone tests, the compressive strength obtained was equal to 55 MPa. Valluzi et al. [17] carried out also tests in limestone of the North-Eastern of Italy and mortar composed of lime, natural hydraulic lime, and sand (3:1:12), with a ratio lime/sand equal to $1: 3$ and a ratio water/lime equal to 0.5 by volume. The compressive strength of the limestone was approximately $160 \mathrm{MPa}$, and the compressive strength of the mortar, after 28 days, was $1.57 \mathrm{MPa}$.

In order to determine the Young's modulus, the Poisson ratio, and the compressive and the tensile strengths of masonry, 10 wallets were prepared for axial and diagonal compression tests. The specimens are square with $1.0 \mathrm{~m}$ side and thickness equal to $0.17 \mathrm{~m}$ (thickness of the walls of the model at 1:3 reduced scale). The compressive strength is on average equal to $6.00 \mathrm{MPa}$, assuming a uniform stress in the cross section of the wallets. This value is rather high with respect to the one obtained by Silva and Soares [18] (0.8 to $1.5 \mathrm{MPa})$ in tests on load-bearing walls of 'gaioleiro' buildings, which is explained by the usage of single leaf walls, higher strength mortar, and larger size stone units. The Young's modulus is equal to $3.37 \mathrm{GPa}$ and presents a large coefficient of variation (20\%). Still, the Grubbs and Dixon criteria [19] indicated that no outliers are present.

In the standard interpretation of the diagonal compression test, the diagonal tensile strength is obtained by assuming that the specimen collapses when the principal stress, $\sigma_{I}$, at its center achieves its maximum value. According to Frocht theory [20], as reported by Calderini et al. [21], the principal stresses at the center of the specimen are equal to: $\sigma_{I}$ (tensile strength) $=0.5 P / A$ and $\sigma_{I I}=-1.62 P / A$, in which $P$ is the load, and $A$ is the transversal area of the specimen. The tensile strength is equal to $0.10 \mathrm{MPa}$.

In what concerns floors, the Young's modulus of the timber joists is about $12 \mathrm{GPa}$. The in-plane behavior of the floors composed of the MDF panels was not tested. However, it is expected that the floors present a rather flexible behavior (Young's modulus lower than $0.5 \mathrm{GPa}$ ), due to the low thickness of the MDF panels $(0.012 \mathrm{~m})$ and joints.

\subsection{Test setup and instrumentation}

The tests were carried out in the LNEC 3D shaking table. This facility allows developing seismic tests in which the global movements are the combination of three translational degrees of freedom according 
with the orthogonal axes (two horizontal), i.e. transversal and longitudinal, and one vertical. The shaking table consists of three main components: (a) the platform in which models are placed, (b) the guiding system, which ensures that the table moves only in the desired degrees of freedom, and (c) the hydraulic actuators that include the control system and impose the movements to the table. The platform is a welded steel slab with a shape similar to a triangular prism, in which the top $(4.60 \times 5.60 \mathrm{~m} 2)$ corresponds to the side where the models are fixed. The whole structure is stiff and with moderate self-weight. The guiding system ensures that the platform only moves in the desired translational degrees of freedom, avoiding rotational movements around the orthogonal axes. For that purpose the system has external torsional bars connected to the table that control the movements of the shaking table. The actuator system is composed by hydraulic actuators and an associated control system. Each of the actuators is composed by a hydraulic cylinder with double effect (tension-compression), possessing one or more servo-valves and a set of hydraulic components, control and safety commands [22].

In shaking table tests, displacement transducers (linear variable differential transformer) and accelerometers are usually used to measure the response of models. Here, the large dimensions of the models and the measurements devices available in the LNEC led to the selection of accelerometers to capture the out-of-plane response of the masonry walls. The signals of the seismic action applied at the base of the models were measured by accelerometers and linear variable differential transformers pre-installed on the platform and on the actuators. In both type of tests, a setup composed by five accelerometers in each masonry wall peer floor level was adopted, resulting in 20 accelerometers for each wall. In total, 80 out-of-plane accelerations of the models were measured, giving detailed information of the out-of-plane response of the masonry walls (Figure 4).

The acquisition of the 84 channels ( 80 output acceleration channels, two input acceleration channels fixed to the platform of the shaking table, and two input displacement channels fixed to the actuators) were carried using two SCXI chassis of National Instruments connected by a trigger. Modules NI SCXI-1530 and NI SCXI-1140 (National Instruments, Austin, Texas, USA) were used for signal conditioning of accelerations and displacements. The damage occurring in the models was registered for each seismic test by photos, video, and drawings of the cracks after each seismic test.

\subsection{Input signals}

The seismic action is composed by two orthogonal and uncorrelated accelerograms. Thus, two artificial accelerograms were generated based on stochastic methods and techniques of finite fault modeling, with parameters adequate for Portugal [23] and a duration equal to $30 \mathrm{~s}$ (intense phase), see Figure 5. The response spectrum of the accelerograms is compatible with the type 1 design response spectrum defined by Eurocode 8 [8] and Portuguese National Annex for Lisbon $\left(a g_{r}=1.5 \mathrm{~m} / \mathrm{s}^{2}\right)$, with a damping ratio equal to $5 \%$ and a type A soil (rock, $S=1$ ). Because of the Cauchy law of similitude (Table I), the acceleration was increased and the time was decreased three times, respectively. The target $P G A$ of the earthquake $100 \%$ in the longitudinal and transversal direction is equal to 4.66 and $4.63 \mathrm{~m} / \mathrm{s}^{2}$, respectively (Figure 5).

\section{SHAKING TABLE TESTS RESULTS}

In this section, the results of the tests carried out at LNEC 3D shaking table are presented. The methodology used for analyzing the results is first presented, followed by the discussion on the crack patterns and the different results obtained in the dynamic identification tests and seismic tests.

\subsection{Methodology used in the analysis of the dynamic identification tests}

The dynamic identification tests aim at estimating the dynamic properties, namely the frequencies, mode shapes, and damping ratios of the models. Dynamic identification was carried out before the first seismic test and after each seismic test, aiming at evaluating the variation of the properties as a function of the seismic action amplitude. The change of the dynamic properties, such as the decrease of the frequencies, 

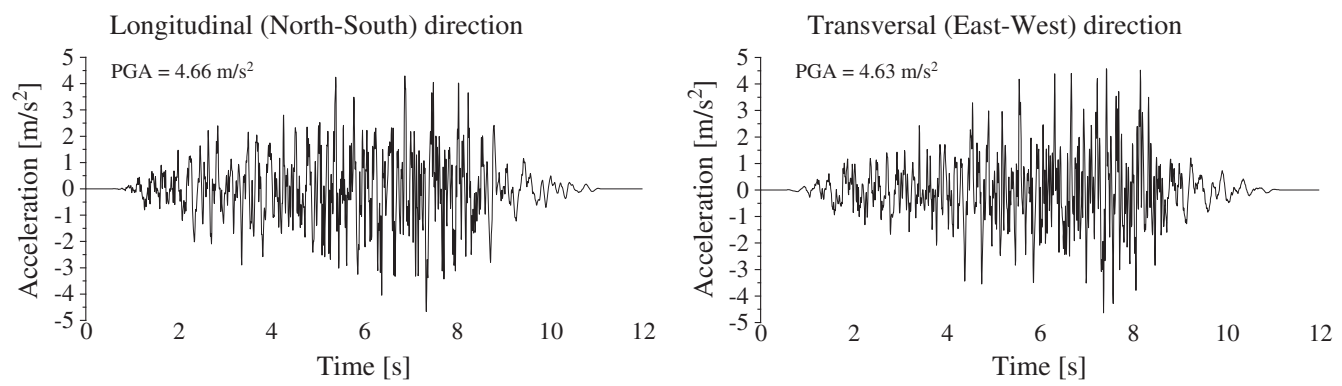

(a)
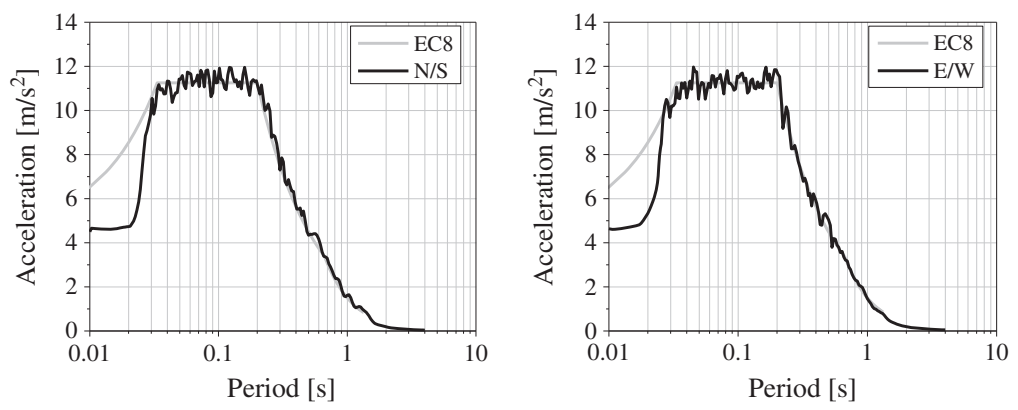

(b)

Figure 5. Input signals at 1:3 reduced scale: (a) time histories; (b) pseudo acceleration response spectrums. (Fourier filter: $0.7-40 \mathrm{~Hz} ; 1.428-0.025 \mathrm{~s}$ ).

is related to the stiffness of the structure and, consequently, to the damage concept usually used to define the degradation of the mechanical properties of materials. Thus, the main objective of these tests is to define a damage indicator based on the decrease of frequencies and to compare the seismic performance of the models (strengthened versus nonstrengthened).

The fundamental relation between natural frequency, mass, and stiffness of a single degree of freedom system [24] is adopted:

$$
\begin{gathered}
\omega_{i, n}{ }^{2}=\frac{K_{i, n}}{M_{i, n}} \\
\left(2 \pi f_{i, n}\right)^{2}=\frac{K_{i, n}}{M_{i, n}}
\end{gathered}
$$

where $\omega$ is the natural frequency, $K$ is the generalized stiffness, $M$ is the generalized mass, and $f$ is the frequency of mode $n$ in the dynamic identification test $i$. Assuming that isotropic damage [25] occurred between the first dynamic identification (DI 0 ) and the dynamic identification $n$, the stiffness reads

$$
K_{i, n}=\left(1-d_{2, i, n}\right) K_{i, 0}
$$

and the $d_{2}$ damage indicator of the mode $i$ in the dynamic identification $n$ is equal to

$$
d_{2, i, n}=1-\frac{M_{i, n} f_{i, n}^{2}}{M_{i, 0} f_{i, 0}^{2}}
$$

Assuming that the modes' shapes do not change significantly throughout the testing, the damage indicator $d_{2}$ can be approximated by 


$$
d_{2, i, n}=1-\left(\frac{f_{i, n}}{f_{i, 0}}\right)^{2}
$$

where the damage indicator $d_{2}$ is proportional to the quadratic ratio between the frequency of the $n$ and the first dynamic identification tests, that is, the damage is a linear function of the variation of the stiffness. The damage indicator ranges from zero (initial condition and theoretical absence of damage) to one (collapse of the structure or full damage). This formulation can be linked to simple models where damage occurs by breakage of parallel fibers, such as pure tension. The first transversal mode of the models which provides the highest contribution to the dynamic behavior, is mainly related to the bending stiffness. The bending stiffness change has a cubic relationship with the damage, understood here as a reduction of the cross section by losing the extreme fibers. Taking into account the variation of the bending stiffness, an alternative damage indicator $d_{2 / 3}$ can be proposed according to the following equation:

$$
d_{2 / 3, i, n}=1-\left(\frac{f_{i, n}}{f_{i, 0}}\right)^{\frac{2}{3}}
$$

As the dynamic behavior of the models depends on several modes, which can hardly be related to a given failure mode, an intermediate relationship between variation of stiffness and damage is adopted next. For simplicity, the damage indicator $d$ is assumed to be linearly proportional to the ratio between the frequency $n$ and the first frequency in the dynamic identification tests:

$$
d_{i, n}=1-\frac{f_{i, n}}{f_{i, 0}}
$$

Figure 6 presents the three damage indicators discussed as a function of the seismic amplitude, assumed to be proportional to the frequency change. The evolution of the damage indicator is significantly different in the three models. For instance, if the seismic amplitude is equal to half of the amplitude that causes the collapse of the structure, the level of damage is equal to $0.75,0.50$, and 0.37 according the $d_{2,} d$ and $d_{2 / 3}$ formulations, respectively.

This formulation used to evaluate the damage is only valid if the mode shapes do not change significantly during testing. Therefore, the Modal Assurance Criterion (MAC) was used to compare the change in the modes' shapes [26]:

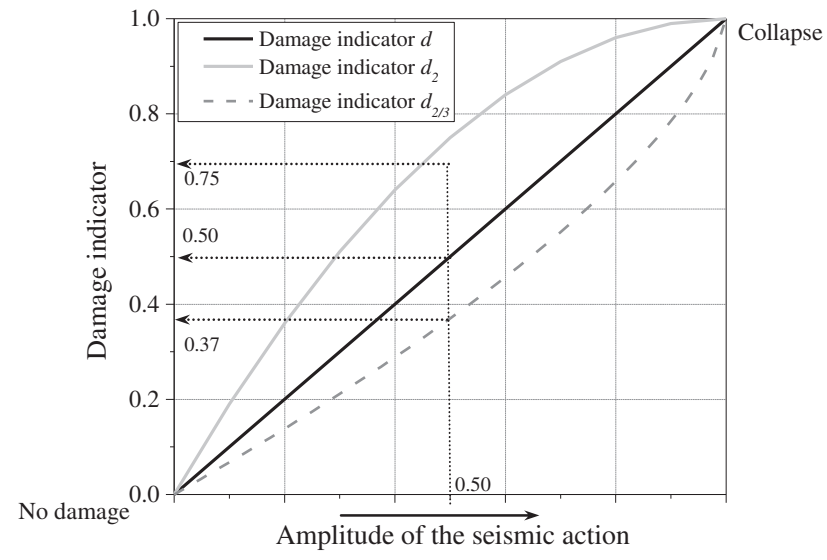

Figure 6. Evolution of the damage indicator as a function of the amplitude of the seismic action. 


$$
M A C_{u, d}=\frac{\left|\sum_{j=1}^{m} \phi_{j}^{u} \phi_{j}^{d}\right|^{2}}{\sum_{j=1}^{m}\left(\phi_{j}^{u}\right)^{2} \sum_{j=1}^{m}\left(\phi_{j}^{d}\right)^{2}}
$$

where $\phi^{u}$ and $\phi^{d}$ are the eigenvectors for two different dynamic identification tests, and $m$ is the number of degrees of freedom. The MAC value ranges from 0 to 1 , corresponding to the absence of correlation or perfect match between the two eigenvectors. The eigenvectors were normalized in a way that the maximum value of the modal displacement is equal to 1 .

\subsection{Methodology used in the analysis of the seismic tests}

In the seismic tests of the models the total accelerations were obtained directly from the accelerometers, while the total velocities and displacements were obtained from the integration of the acceleration. The relative velocities and displacements of the models were obtained subtracting the total velocities and displacements from the respective values at the base of the models. It is noted that 80 accelerometers (five at each floor level of each wall) were used to measure the response of the models and that four and six seismic tests were carried out on the NSMs and SMs, respectively (in the earthquake $150 \%$ of the SM, the response was not measured). Thus, a total of 960 and 1200 signals of the response of the models (acceleration, velocities, and displacements) were processed.

As the number of measured signals is high and it is difficult to use all signals to compare the performance of the models along the testing program, the response of the models was analyzed by merging the signals of acceleration and relative displacements at the floor levels. Thus, the performance of the models was evaluated by using only four parameters of response at the floor levels for each masonry wall, namely:

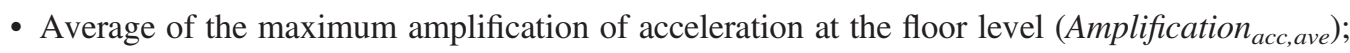

- Average of maximum out-of-plane displacements at the floor levels $\left(u_{\text {ave }}\right)$;

- Average of out-of-plane displacements with respect to the corners at the floor levels $\left(u_{\text {ave }}\right)$;

- Average of the maximum drifts obtained from the vertical alignments on the left and right of the

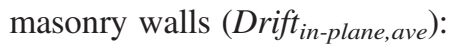

The four parameters of the response of the models at the floors levels (Amplification ${ }_{\text {acc,ave }}, u_{\text {ave, uave, }}$ corners and Drift $\left.t_{\text {in-plane,ave }}\right)$ were related to the nominal peak ground acceleration $\left(P G A_{n o}\right)$ applied at the base.

\subsection{Crack patterns}

In the first seismic tests, the NSM does not present significant damage. Only a few cracks are observed. However, as shown in the results of the dynamic identification tests, after this seismic test, the NSM presents a significant reduction in the frequency of the first mode. This may be related to microcracks that occurred in the mortar during the earthquake $25 \%$, which are not visible in the end of the seismic test because of the self-weight action or floor action. During the dynamic identification, the micro-cracks can decrease the frequency of the first transversal mode. During the earthquakes $50 \%$ and $75 \%$, the damage increases, as expected, concentrating in the spandrels. The corners of the openings have large concentration of stresses and, consequently, cracking occurs. In the earthquake $75 \%$, some separation between the floors at the third floor and the east gable wall is also observed. The gable walls do not present significant damage.

After earthquake $100 \%$, the model presents a high concentration of damage at the facades (Figure 7(a)). Almost all the spandrels present damage caused by diagonal tension, related to the in-plane behavior of the facades. Furthermore, almost all piers at the fourth floor present horizontal cracks, either at the ends or within the height of the element. The first horizontal cracks are mainly related to the in-plane behavior of the facades, with in-plane rocking of the piers. On the other hand, the horizontal cracks within the height of the element are mainly related to the out-of-plane bending of the piers. It is known that the vertical compressive stress is favorable to the behavior of the masonry under 


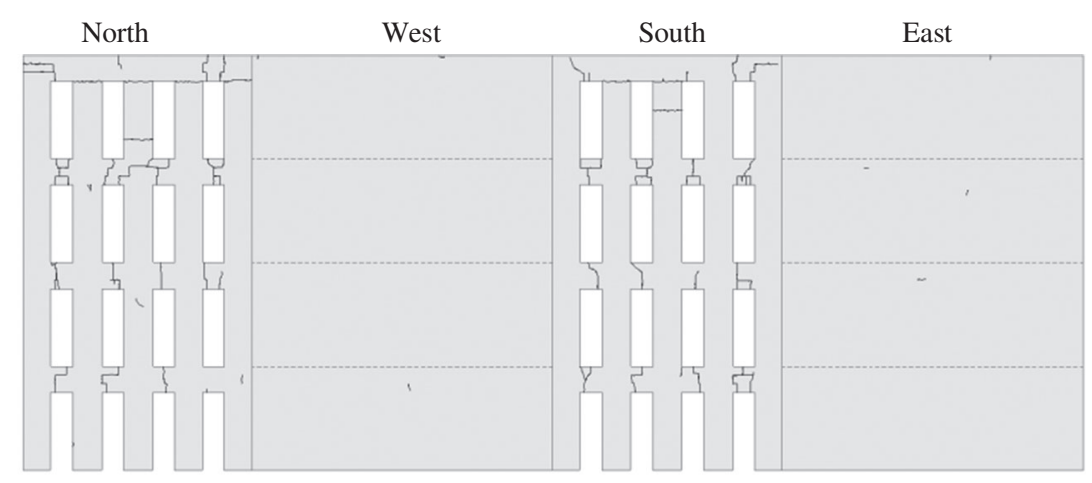

(a)

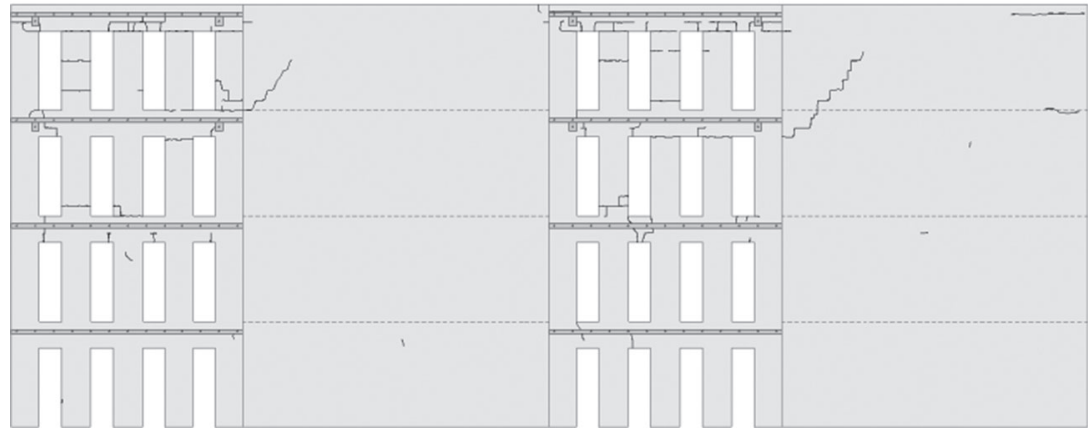

(b)

Figure 7. Crack patterns of the Earthquake 100\%: (a) non-strengthened model; (b) strengthened model.

horizontal loads, preventing in-plane and out-of-plane collapse mechanisms. Taking into account that the axial force at the top of the model is low, the piers at the fourth floor are more vulnerable to the horizontal loads, as shown in the cracks patterns. Contrarily to what is observed in the facades, the gables walls do not present any significant damage. The timber floors and corners do not also present any damage, and the MDF panels remain connected to the timber joists.

As previously mentioned, after earthquake $100 \%$, the NSM was repaired, aiming at re-establishing its initial condition. However, the crack pattern of the SM presents a horizontal crack at the central pier of the north facade with small width after the earthquake $25 \%$, leading to the conclusion that the NSM was not adequately repaired in this area. Except for this crack, after the earthquake 25\%, the SM does not present other any damage and, as shown later from the dynamic identification tests, the frequency of the first transversal mode exhibits a very low decrease.

After the earthquakes $25 \%, 50 \%$, and $75 \%$, the SM presents crack patterns significantly different from the ones obtained for the NSM. After earthquake 75\%, the facades of the SM present low damage at the spandrels and only a few horizontal cracks at the two top floors. After earthquake $100 \%$ (Figure 7(b)), the damage in the SM concentrates at the top floors, mainly at the facades. In comparison to the NSM, this model presents less damage at the spandrels, leading to the conclusion that the steel plates and angles improved the performance of the lintels with respect to the diagonal tension collapse mechanism. The piers of the two top floors present several horizontal cracks, which are related to the in-plane rocking and out-of-plane bending of the piers. It is noted that the strengthening elements modify the boundary condition of the piers, decreasing the out-of-plane displacements at their ends. Thus, and because of the out-of-plane inertial forces, the relative displacements between a point at the interior and the ends of piers increase, causing the observed horizontal cracks. However, these horizontal cracks present very low thickness.

During the earthquake $100 \%$, the gable walls of the SM present diagonal cracks, indicating that part of the out-of-plane inertial forces of the facades was transferred by the strengthening elements to the gable walls. The masonry near the anchors of the steel cables presents damage, leading also to the conclusion that the steel cables are able to transfer the inertial forces from the facades to the gables 


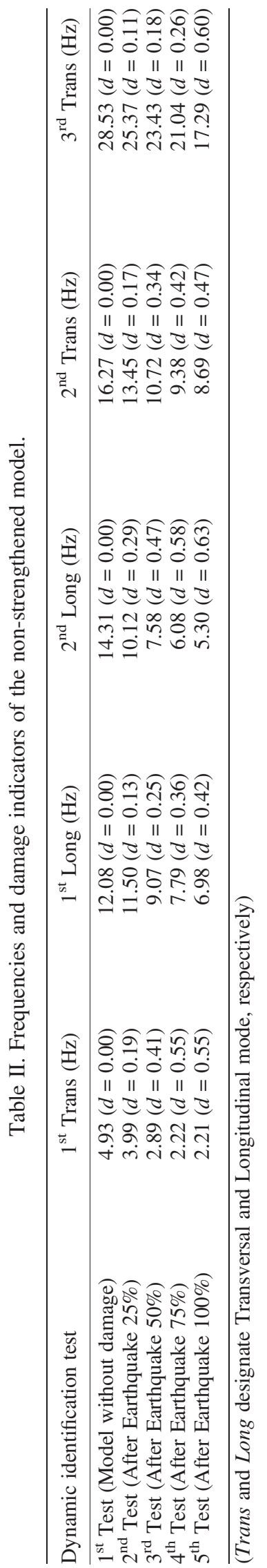


walls. The floors do not present damage. Thus, the strengthening elements improved the seismic performance of the model, reducing the damage at the spandrels, transferring inertial forces from the facades to the gable walls and, consequently, taking advantage of the strength of each structural element of the model. As the SM presents moderate damage at this stage, for which the global collapse of the facades is not expected, two larger amplitude seismic tests were carried out.

After the last seismic test, for earthquake $150 \%$, the damage of the SM concentrates at the two top floors, with cracks at the spandrels, at the piers and at the joints spandrel/pier. The damage at the two first floors is low in comparison with the one observed in the NSM even for earthquake 100\%. The cracks at the spandrels are mainly related to the diagonal tension caused by the in-plane behavior of the facades. However, the spandrels remain connected by the steel strengthening elements. The inplane rocking and out-of-plane bending of the piers at the fourth floor were clearly observed. The central pier at the floor of the north facade collapsed, which may be related to the initial damage of the SM, because the opposite pier at the south facade did not collapse, and after the weak earthquake $25 \%$, a horizontal crack at the pier at the north facade was observed. Furthermore, the gable walls present diagonal cracks due to the in-plane behavior, indicating that the strengthening elements were able to transfer the out-of-plane inertial forces from the facades to the plane of the gable walls and to prevent the global collapse of the facades. The gable walls present also horizontal cracks at the third floor, which are caused by the out-of-plane response of the walls at the top of the model and are related to the high out-of-plane inertial forces and low in-plane vertical forces.

\subsection{Dynamic identification tests results}

In the first dynamic tests of the NSM, eleven mode shapes, ranging from $4.93 \mathrm{~Hz}$ to $33.22 \mathrm{~Hz}$, were estimated. The first mode is a transversal mode, as expected, and its frequency is equal to $4.93 \mathrm{~Hz}$. The frequency of the first longitudinal mode is equal to $12.08 \mathrm{~Hz}$, which is significantly higher than the frequency of the first transversal mode, because the model is much stiffer in the longitudinal direction. The transversal modes are associated to the global behavior of the model and were clearly identified. The longitudinal modes are mainly related to the local behavior of the facades. The vulnerability curves were defined considering the damage indicator $d$ (Equation (9)), for each mode, with the input of the seismic tests in terms of nominal peak ground acceleration $\left(P G A_{n o}\right)$. Here, only the five modes in which the frequencies could be estimated in all dynamic tests were considered. Although the damage influences all the modes, the stiffness components of the structural elements do not have the same contribution for all modes and, consequently, different variations in the frequencies of the modes are found (Table II). During testing, the first transversal mode presented on average MAC is equal to 0.95 . The others' modes presented lower MACs (lower than 0.80). This means that, although the mode shape is similar, the mode is not exactly the same because of the damage that occurred.

In the SM, six dynamic identification tests were done. Because of the serious damage of the model it was not possible to carry out the dynamic identification after the earthquake $150 \%$. In the first dynamic identification test, nine modes were estimated and related to the ones obtained for the NSM. The frequency of the first mode is equal to $4.51 \mathrm{~Hz}$, which is a decrease of about $8.5 \%$ and presents the highest MAC (about 0.96) with respect to the first transversal mode estimated in the NSM. During testing, only four modes were estimated in all dynamic identifications (Table III). The first transversal mode presents the highest MAC (about 0.98).

Table III. Frequencies and damage indicators of the strengthened model.

\begin{tabular}{llrrl}
\hline Dynamic identification test & $1^{\text {st }}$ Trans $(\mathrm{Hz})$ & $1^{\text {st }}$ Long $(\mathrm{Hz})$ & $2^{\text {nd }}$ Trans $(\mathrm{Hz})$ & $3^{\text {rd }}$ Trans $(\mathrm{Hz})$ \\
\hline $1^{\text {st }}$ Test (Model without damage) & $4.51(d=0.00)$ & $13.37(d=0.00)$ & $15.62(d=0.00)$ & $25.83(d=0.00)$ \\
$2^{\text {nd }}$ Test (After Earthquake 25\%) & $4.48(d=0.01)$ & $13.06(d=0.02)$ & $13.82(d=0.12)$ & $25.13(d=0.03)$ \\
$3^{\text {rd }}$ Test (After Earthquake 50\%) & $4.15(d=0.08)$ & $12.39(d=0.07)$ & $12.67(d=0.19)$ & $22.87(d=0.11)$ \\
$4^{\text {th }}$ Test (After Earthquake 75\%) & $3.65(d=0.19)$ & $10.86(d=0.19)$ & $10.79(d=0.31)$ & $20.68(d=0.20)$ \\
$5^{\text {th }}$ Test (After Earthquake 100\%) & $3.17(d=0.30)$ & $9.77(d=0.27)$ & $9.94(d=0.36)$ & $16.90(d=0.35)$ \\
$6^{\text {th }}$ Test (After Earthquake 125\%) & $2.75(d=0.39)$ & $9.64(d=0.28)$ & $7.74(d=0.50)$ & $13.67(d=0.47)$ \\
\hline
\end{tabular}

(Trans and Long designate Transversal and Longitudinal mode, respectively) 
In the comparison of the seismic performance of the models, the vulnerability curves for the first mode were used (Figure 8). The first mode is a global mode with the highest mass contribution, and presented the highest MAC values between the models and during the testing. The higher modes of the non-strengthened model, namely the longitudinal modes, are out-of-plan modes of the facades (local modes). The longitudinal modes of the strengthened model are global modes, because of the out-ofplan displacements at the facades by strengthening elements are prevented, resulting in low MAC values with respect to the modes estimated for the strengthened model. Even the second and third transversal modes presented low MAC values between the models. Thus, the higher modes are not appropriated to make a direct comparison of the seismic performance of the non-strengthened and strengthened models. It is known that higher modes not estimated in this work, as the local modes of the piers of the top floors, have influence on the seismic performance of the models. However, the damage caused by these modes also influences the stiffness and the damage indicator of the first mode.

The highest variation of the damage indicator occurred in the earthquake $25 \%$, as there is almost no damage for the SM at this stage. In the earthquake 100\%, the SM presents a reduction of the damage indicator of about $46 \%$ with respect to the NSM, leading to the conclusion that the strengthening was efficient in decreasing the seismic vulnerability of the model. Even in the earthquake $125 \%$, the damage indicator of the SM (0.39) is lower than the damage indicator of the NSM in the earthquake $100 \%(0.55)$.

\subsection{Seismic tests results}

In the comparison of the main results of the seismic tests, seven parameters to control the response of the model were related to the amplitude of the seismic action $\left(P G A_{n o}\right)$ : (i) two average maximum acceleration amplification at the third floor of the facades and at top of the gable walls

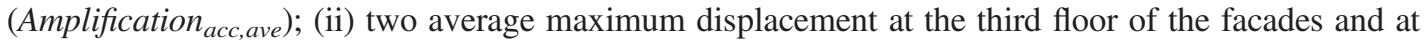
top of the gable walls $\left(u_{\text {ave }}\right)$; (iii) two average maximum relative displacement with respect to the corners at the third floor of the facades and at the top of the gable walls $\left(u_{\text {ave,corners }}\right)$; and (iv) the average maximum in-plane drift at the third floor of the facades (Drift $t_{\text {in-plane,ave }}$ ). The locations to control the response correspond to the floors in which the NSM presents the maximum values. It is stressed again that the results here presented correspond to the average of the results of the facades and to the average of the results of the gable walls. It is also noted that the $P G A$ in the longitudinal direction of the earthquake $100 \%$ measured at the base of the SM is higher than the target one.

The third floor of the facades of the NSM presents a progressive decrease of the Amplification acc,ave after earthquake $50 \%$ and is significantly higher than the SM. Even if it presents significant low Amplification $_{\text {acc,ave }}$ in the first seismic tests, in the earthquake $100 \%$, the SM presents an amplification $8 \%$ higher than the NSM (Figure 9(a)). In earthquake 100\%, the top of the gable walls

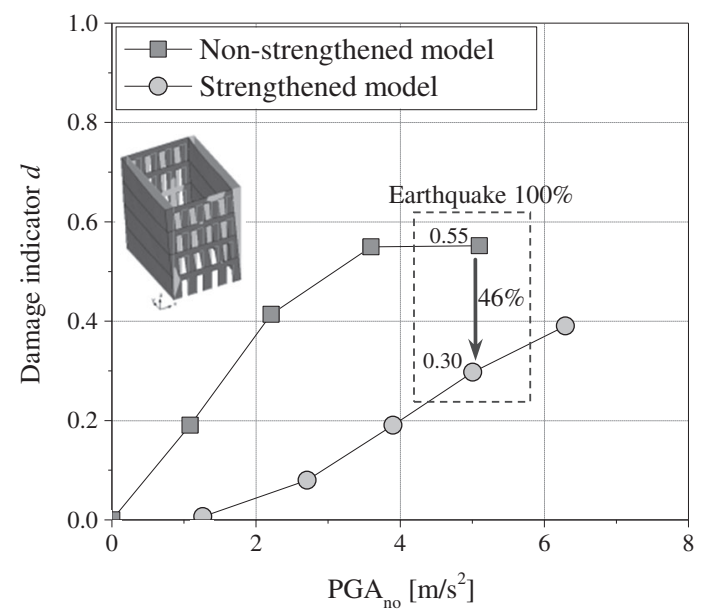

Figure 8. Seismic vulnerability curves using the first mode and grades of damage according to the European Macroseismic Scale 1998 [27]. 


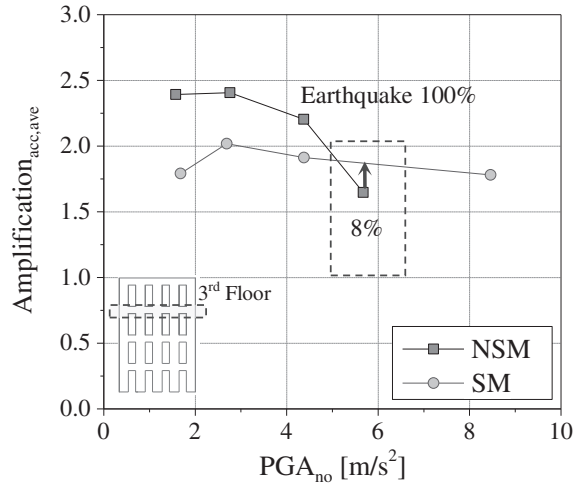

(a)

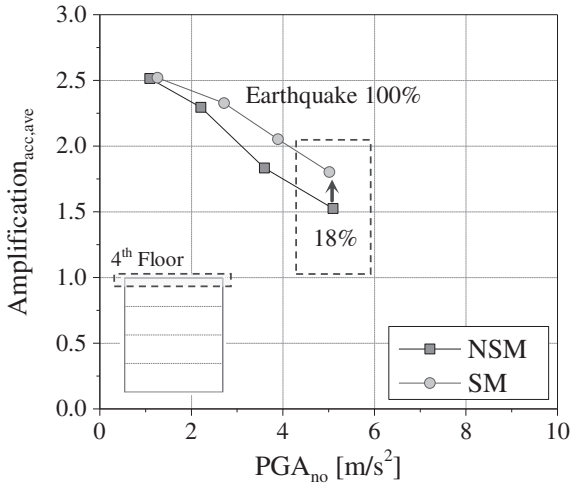

(b)

Figure 9. Comparison of the average out-of-plane acceleration amplification at the (a) $3^{\text {rd }}$ floor of the facades and (b) $4^{\text {th }}$ floor of the gable walls.

(Figure 9(b)) of the SM presents also amplification higher than the NSM (18\%). This means that the SM presents lower degradation of the stiffness and, consequently, less damage than the NSM, leading to the conclusion that the strengthening technique improved the seismic performance of the model.

In what concerns the average maximum displacement $\left(u_{\text {ave }}\right)$, the third floor of the facades of the SM (Figure 10(a)) presents a reduction of $20 \%$ with respect to the NSM for earthquake $100 \%$. This means that the strengthening elements improved the out-of-plane response of the facades. However, in the earthquake $100 \%$, the top of the gable walls of the SM only presents a reduction of about $8 \%$ (Figure 10(b)). It is noted that the displacements $u_{\text {ave }}$ are mainly a global parameter of the response of the models in the longitudinal and transversal directions, which are obtained from the average of the maximum displacements of the five vertical accelerometers, including the two corners, occurring at different times of the seismic test.

The displacement $u_{\text {ave,corners }}$ is a local parameter of the response of the masonry walls and allows evaluating the out-of-plane response with respect to the corners. In the earthquake $100 \%$, the third floor of the facades of the SM presents a significant reduction of the local out-of-plane response $(68 \%)$ with respect to the NSM (Figure 11(a)), as expected. The top of the gables walls of the SM (Figure 11(b)) also presents a significant reduction in the local out-of-plane deformation (48\%). Thus, the strengthening of the connections of the timber floors, mainly the joists, with the gable walls and the steel angles improved also the local out-of-plane response of these walls.

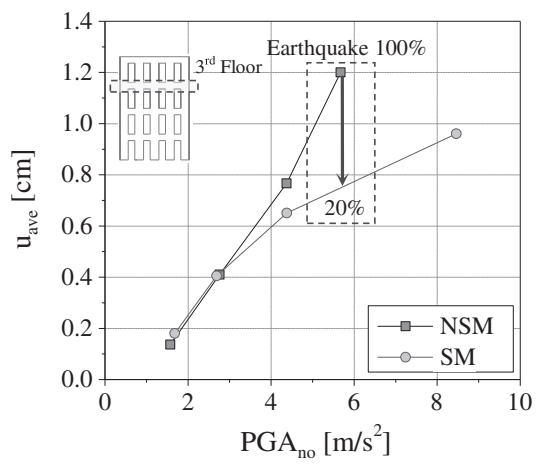

(a)

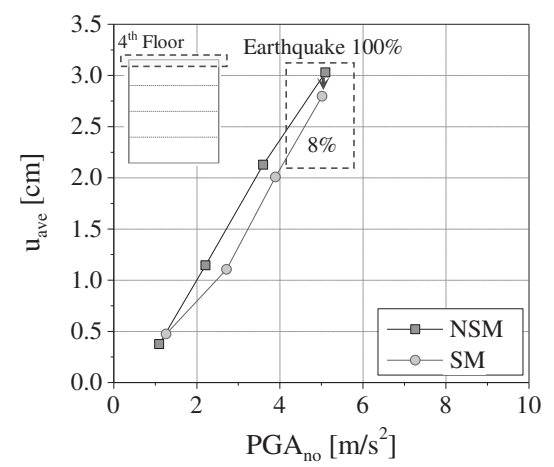

(b)

Figure 10. Comparison of the average out-of-plane displacement at the (a) $3^{\text {rd }}$ floor of the facades and (b) $4^{\text {th }}$ floor of the gable walls. 


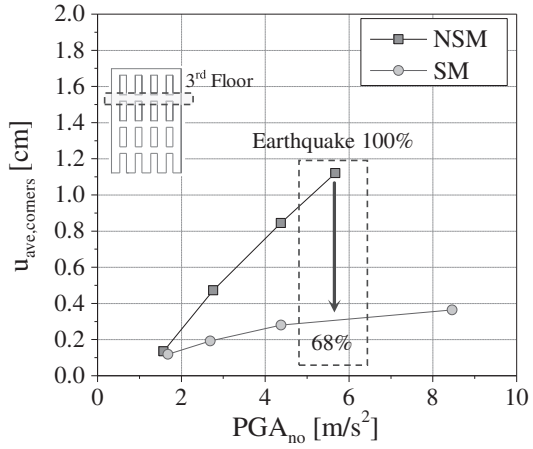

(a)

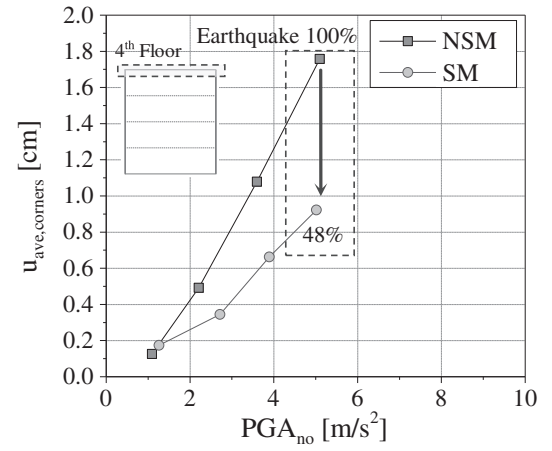

(b)

Figure 11. Comparison of the average out-of-plane relative displacement with respect to the corners at the (a) $3^{\text {rd }}$ floor of the facades and (b) $4^{\text {th }}$ floor of the gable walls.

Finally, the efficiency of the strengthening technique was also evaluated using the average maximum in-plane drift (Drift $t_{\text {in-plane,ave }}$ ) at the third floor of the facades. In the earthquake $100 \%$, the Drift $_{\text {in-plane,ave }}$ of the NSM presents a reduction of about $31 \%$ with respect to the NSM (Figure 12). As expected, the steel angles and plates applied at the floor levels of the facades ensure that the masonry structural elements (spandrels and nodes spandrel/pier) remain connected, improving the in-plane response of the second and third floors, which resulted in a reduction of the in-plane relative displacements between these two floors.

\section{CONCLUSIONS}

This paper discusses the results of the shaking table tests of an existing stone masonry building, with and without strengthening. The crack patterns shows that, for the design earthquake in Lisbon, the NSM presents a higher concentration of damage at the facades, in almost all spandrels. Furthermore, almost all piers at the fourth level in the facade present horizontal cracks, due to in-plane rocking and out-of-plane bending. The gable walls, timber floors, and corners do not present any damage. In general, the NSM presents substantial damage, corresponding to a grade 3 for masonry buildings, according to the European Macroseismic Scale 1998 [27]. Although the collapse of the NSM was not achieved, it is expected that with the increase of the seismic amplitude, the damage concentrates at the spandrels and at the top piers, leading to the partial or global collapse of facades, which is common in buildings with flexible floors.

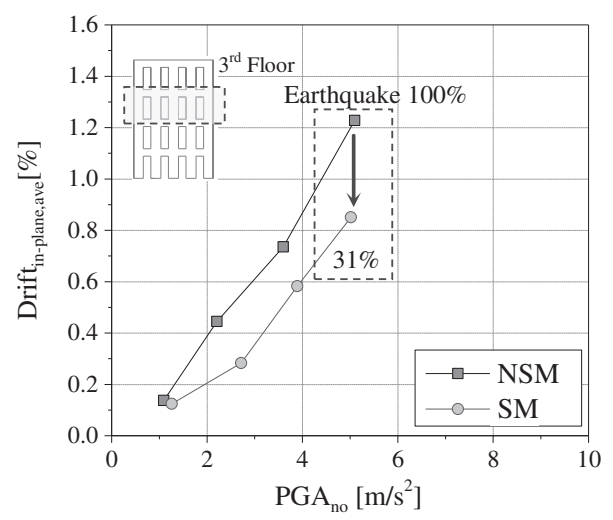

Figure 12. Comparison of the average in-plane drift at the 3rd floor of the facades. 
The model was prepared on a reduced scale 1:3, taking into account the Cauchy similitude law. If the Cauchy and Froude similitude laws would have been respected, additional masses had to be added to the model, which would increase the normal stress at the piers. Thus, it is expected that a reduced model respecting the Cauchy and Froude similitude laws or a full model (prototype) present higher strength, namely with respect to the rocking mechanism of the piers at top floor, than the reduced model prepared using only the Cauchy similitude law. This is being addressed by numerical simulation and will be the subject of a subsequent communication.

The damage of a repaired and lightly SM (for the same design earthquake) concentrates at the top floors, mainly at the facades. The gable walls of the SM present diagonal cracks, indicating that part of the out-of-plane inertial forces of the facades was transferred by the strengthening elements to the gable walls. In comparison to the NSM, this model presents moderate damage (grade 2), leading to the conclusion that the repair was efficient, and that the strengthening elements improved the seismic performance of the buildings.

The results of the dynamic identification were used to obtain the experimental seismic vulnerability curves of the models based on the relationship between a quantitative damage indicator and the seismic amplitude applied at the base. The damage indicator $d$ is based on the decrease of the frequencies of the modes during testing. For the design earthquake and for the first transversal mode, the SM presents a reduction of the damage indicator $d$ of about $50 \%$ with respect to the NSM, leading to the conclusion that the strengthening technique was efficient in the reduction of the seismic vulnerability of the building.

The results of the seismic tests show also that the strengthening technique improved the seismic performance of the model, mainly at the floor levels of the facades and gables, which present the largest deformation in the NSM. Besides an improvement of the out-of-plane response, the strengthened model also presented a significant improvement in the in-plan response and energy dissipation capacity, with a reduction of about $30 \%$ in the in-plane drift at the third floor (Earthquake 100\%).

Taking into account the results from the shaking table tests, it is concluded that the adopted repair and strengthening technique improved significantly the seismic performance of the models particularly the out-of-plane behavior of the masonry walls, and is an effective solution for reducing of the seismic vulnerability of existing masonry buildings with flexible floors.

\section{ACKNOWLEDGEMENTS}

The first author acknowledges the financial support from the Portuguese Foundation for Science and Technology (FCT) through grant SFRH/BD/32190/2006. The work was also supported by the project 'New Integrated Knowledge based approaches to the protection of cultural heritage form Earthquake-induced Risk' (NIKER FP7-ENV-2009-1-224123) from the European Commission.

\section{REFERENCES}

1. Hough SE, Bilham RG. After the Earth Quakes_Elastic Rebound on an Urban Planet. Oxford University Press, Inc: New York, 2006.

2. U. S. Geological Survey: Science for a changing the world. http://www.usgs.gov [2 December 2012]

3. Tomaževič M, Lutman P, Weiss P. Seismic upgrading of old brick-masonry urban houses: tying of walls with steel ties. Earthquake Spectra 1996; 12(3):599-622. DOI:10.1193/1.1585898

4. Pinho FF. Walls from Ancient Portuguese Buildings. "Edifícios", $\mathrm{N}^{\circ} 8$, National Laboratory for Civil Engineering: Lisbon, Portugal: 2000. ISBN:9789724918648 (In Portuguese).

5. Appleton J. Rehabilitation of "Gaioleiros" Buildings-a Block in Lisbon. Orion edition: Amadora, 2005. ISBN:9728620055 (In Portuguese).

6. Lindt JW, Pryor SE, Pei S. Shake table testing of a full-scale seven-story steel-wood apartment building. Earthquake Structures 2011; 33(3):757-766. DOI:10.1016/j.engstruct.2010.11.031

7. Moaveni B, He X, Conte JP, Restrepo JI. Damage identification study of a seven-story full-scale building slice tested on the UCSD-NEES shake table. Structural Safety 2010; 32(5):397-409. DOI:10.1016/j.strusafe.2010.03.006

8. EN 1998-1. Eurocode 8: Design of Structures for Earthquake Resistance-General Rules, seismic actions and rules for building. European Committee for Standardization, 2004.

9. Degée H, Denoël V, Candeias P, Campos-Costa A, Coelho E. Experimental Investigation on the Seismic Behaviour of North European Masonry Houses. 7th National Congress on Seismology and Earthquake Engineering ("Sísmica 2007”): Porto, Portugal, 2007 (In Portuguese). 
10. Bairrão R, Falcão M. Shaking table tests of two different reinforcement techniques using polymeric grids on an asymmetric limestone full-scaled structure. Engineering Structures 2009; 31(6):1312-1330. DOI:10.1016/j. engstruct.2008.04.039

11. Candeias P. Seismic Vulnerability Assessment of Ancient Buildings. PhD Thesis, University of Minho, Guimarães, Portugal, 2008. (http://hdl.handle.net/1822/9057) (In Portuguese).

12. Sonin AA. The Physical Basis of Dimensional Analysis. Department of Mechanical Engineering, Massachusetts Institute of Technology (MIT): Cambridge, 2001.

13. Carvalho EC. Seismic Testing of Structures. 11th European Conference on Earthquake, Paris, France, Balkema, Rotterdam, 1998; 53-64. ISBN:9054109823

14. EN 196-1. Methods of Testing Cement-Part 1: Determination of Strength. European Committee for Standardization, 2005.

15. ASTM Standard D2938-95. Standard test method for unconfined compressive strength of intact rock core specimens. American Society for Testing and Materials 2002. DOI: 10.1520/D2938-95R02

16. Toumbakari EE. Lime-pozzolan-cement grouts and their structural effects on composite masonry walls. PhD Thesis, Katholieke Universiteit Leuven, Belgium, 2002.

17. Valluzi MR, Porto F, Modena C. Behaviour and modelling of strengthened three-leaf stone masonry walls. Materials and Structures 2004; 37(3):184-192. DOI: 10.1007/BF02481618

18. Silva V, Soares I. Seismic Vulnerability of the "Gaioleiro" Buildings of Lisbon and Possible Measures to Reduce it. 3rd Meeting on Seismology and Seismic Engineering: Technical University of Lisbon, Portugal, 1997 (In Portuguese).

19. ASTM Standard E178-02. Standard practice for dealing with outlying observations. American Society for Testing and Materials, 2002. DOI: 10.1520/E0178-02

20. Frocht M. Recent advances in photoelasticity: and an investigation of the stress distribution in square blocks subjected to diagonal compression. Transactions of the American Society of Mechanical Engineers, Applied mechanics $1931 ; \mathbf{5 3}(15): 135-153$.

21. Calderini C, Cattari S, Lagomarsino S. Identification of the Shear Mechanical Parameters of Masonry Piers from Diagonal Compression Test. 11th Canadian Masonry Symposium: Toronto, Canada, 2009.

22. LNEC: National Laboratory for Civil Engineering, Lisbon, Portugal. http://www.lnec.pt/organization/de/nesde/ ptriaxialcaracteristicas [2 December 2012]

23. Carvalho A. Stochastic Modelling of the Seismic Action in Mainland Portugal. PhD Thesis. Technical University of Lisbon, Portugal, 2007 (In Portuguese).

24. Chopra A. Dynamics of Structures: Theory and Applications to Earthquake Engineering (3rd edn), Prentice Hall, 2001.

25. Lemaitre J, Desmorat R. Engineering Damage Mechanics: Ductile, Creep, Fatigue and Brittle Failures. Springer: New York, 2005.

26. Ewins D. Modal Testing: Theory, Practice and Application (2nd edn), Research Studies Press LTD: Baldock, Hertfordshire, England, 2000.

27. Grünthal G. European Macroseismic Scale 1998: EMS-98. European Seismological Commission, Subcommission on Engineering Seismology, Working Group Macroseismic Scales, Volume 15, 1998. 